\title{
A Survey on Smart use of BBM and its Influence on Academic Achievement in SMK Health PGRI Denpasar
}

\author{
I Wayan Gede Narayana \\ STMIK STIKOM Bali \\ Denpasar, Indonesia
}

\begin{abstract}
Black Berry Messenger chat facility is very popular in the process of communicating through text messages, pictures and videos, so that the process of communication in the interaction between users can be carried out actively in virtual world. In this study, it will be examined as to whether the Black Berry Messenger has a significant influence on academic achievement in SMK Health PGRI Denpasar. This study will show the effect of the BBM in the improvement of academic achievement, using quantitative methods by distributing questionnaires from a random sample of the student population of SMK health PGRI Denpasar. The correlation analysis uses the correlation coefficient Kendall's tau which managed to deliver the results that the $\mathrm{BBM}$ is very influential with the increase of academic achievement.
\end{abstract}

Keywords-Black Berry Messenger; Academic Achievement; Correlation; Simple Random Sampling; Kendall's Tau

\section{INTRODUCTION}

BBM is a very popular chat facility [7] in the process of communicating through text messages, pictures and videos so that the process of communication in the interaction between users can be carried out actively in virtual world. One technology that is used is the chat facility available on smart phones such as BBM. BBM Chat is utilized very effectively by the students especially for the learning process in the exchange of information both material and knowledge sharing.

In entire, the student's personality [6] can be seen from the way they communicate, as a way to exchange information with other friends. Previously, the information exchange process between students used SMS, which has some limitation in sending picture or video. Now, many students use $\mathrm{BBM}$ in the learning process or sharing knowledge. In the study the effect of the BBM on academic achievement, the effect of BBM is examined significantly to know the improvement of academic achievement [9] In the SMK Health PGRI Denpasar. Community students [10] can get more information through BBM .This Research is about the influence of BBM on academic achievement, using quantitative methods by distributing questionnaires from a random sample of the student population SMK health PGRI Denpasar. Quantitative research method can be interpreted as a research method based on positive philosophy, used to examine the population or a particular sample, sampling technique is generally done at random, using a data collection
[3] instrument of research, analysis of quantitative data in order to test the hypothesis that is set.

This research studies the effect of BBM with academic achievement, to determine the positive and negative influences of BBM (Blackberry Messenger), and learning to use the $\mathrm{BBM}$ and increase academic achievement using BBM.

In order to gain insight into the effect of BBM to increase academic achievement in this paper, the following structure is organized. In the second part some background information about the main concept paper will be provided. A more detailed description of the research method used is presented in section 3. Furthermore, the result of research conducted is presented in Section 4. In section 5 the conclusions are drawn.

\section{BACKGROUND}

In this section, every concept and its relationship with the problem at hand are explained.

\section{A. Role of Information Technology}

The role of information [1] technology becomes a key is capable of an information technology provides an exceptional influence in the field of improvement of students everyday learning course where the relationship between education and technology into an extraordinary relevance in the development of future learning.

\section{B. Black Berry Messenger}

BlackBerry Messenger, abbreviated as BBM, is instant messenger application available to BlackBerry device users. This application [7] features the ability to adopt a popular activity among users of mobile devices.

\section{Benefit of Learning Media}

In a learning process, two very important [12]elements are the method of teaching and teaching media, in which these two aspects are interrelated. Selection of one particular teaching method of teaching will affect the type of media used, although there are other aspects that must be considered in choosing the media, among others, the purpose of teaching, types of tasks and a response is expected to take place controlled by the students after teaching and learning context includes the characteristics students. Nevertheless, it can be said that one of the main functions of teaching media is as a teaching aid that also affect the conditions, and the learning environment organized and created by teachers. 


\section{Productivity}

Productivity is the relationship between [2] the amount of output and input quantity for expected output result, it is essentially a measure of the effectiveness and efficiency of the organization in generating output based on those resources available. Productivity is very important for the long-term and profitability, capable to increase if managed hilistikly and systematicly. Identification and measurement of productivity is estimated in accordance with output and input. In productivity output may be expressed in physical quantities, the output can be expressed in physical units, while the input is an act that consists of resources used to produce output, a very common form of input, for example can, be seen from the workforce.

\section{E. Correlation}

Correlation between variables [5] in the mentioned research methodology, is divided into three types, namely the is symmetrical relationship, asymmetrical relationship and reciprocal relationship. Correlation is one of the statistical analysis used to find the relationship between two quantitative variables. Correlation analysis is the study of the discussion about the degree of relationship or the degree of association between two variables, such as variables $\mathrm{X}$ and $\mathrm{Y}$.

\section{RESEARCH METHOD}

The research is conducted at SMK Health PGRI Denpasar for 3 months from March - May 2015.

\section{A. Place dan Time Research}

The research is conducted at SMK PGRI Denpasar Health for 3 months from March - May 2015

\section{B. Systematics Research}

Stages of systematic research as follows:

1) The first stage is the process of identifying things that become factor in the using system of BBM (BlackBerry Messenger) in the field. This process is carried out by performing understanding in the field, literature studies, and previous research studies. Results of the identification process are the analysis of field conditions regarding the use of BBM (Black Berry Messenger).

2) The next step is the establishment of the conceptual model and research plan. In the second stage where the process is carried out is variable identification, the relations among the constructs, as well as the preparation of the research hypothesis. Results of the second stage are a list and description of the variables as well as research instruments. Research instruments adapted to the description of the variables.

3) The next step is data collection, hypothesis testing, and the interpretation of test results. Results of testing the hypothesis that the hypothesis is accepted or rejected.

4) The last process is making a conclusion.

Systematic research can be show by Figure 1.

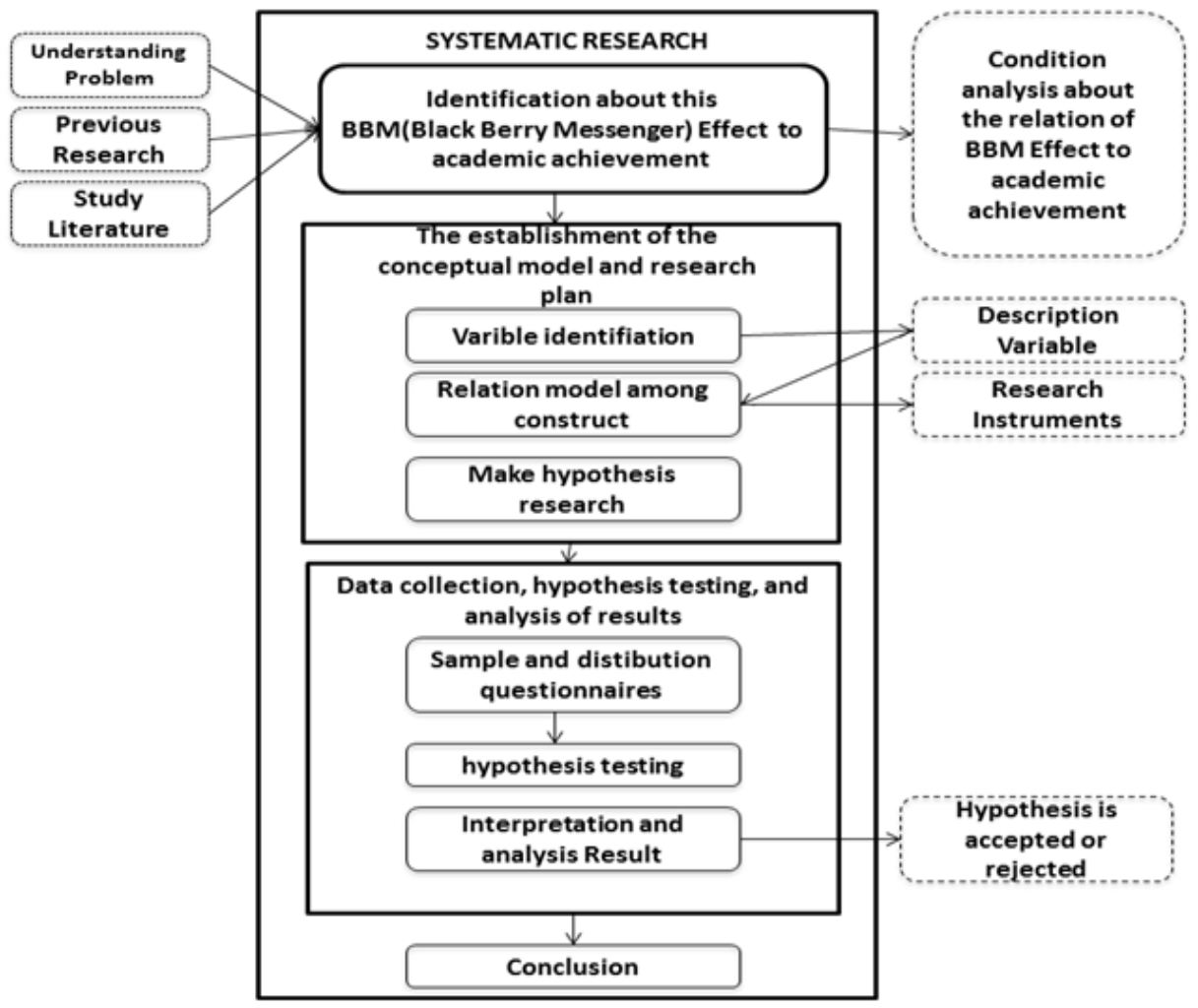

Fig. 1. Systematics Research 


\section{Data Collection Technique}

Data was collected by distributing questionnaires to users of BBM (Black Berry Messenger). Samples taken from the Student of SMK Health PGRI Denpasar sampling technique is simple random sampling. This technique is used [8]when the population has members / elements that are not homogeneous and stratified proportional.

\section{Variable Research}

There are two variables in this study, the use of BlackBerry Messenger and Achievement. The relationship of the four variables is as shown in Figure 2.

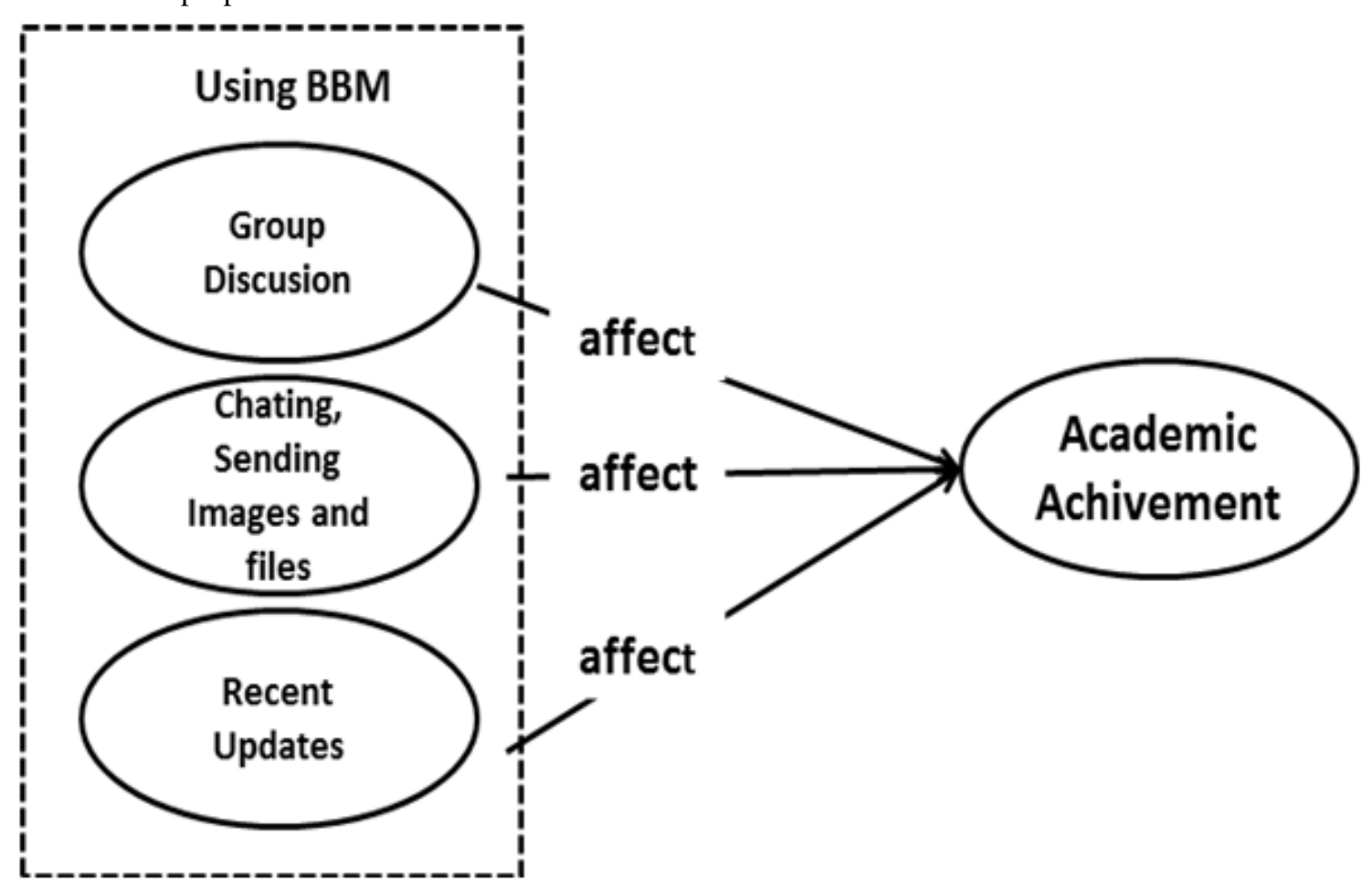

Fig. 2. Relation Model Variable

Definitions of these variables can be explained as follows:

\section{1) Group Discussion}

Group discussion is a feature owned by BBM in a group chat where there are some members who have similarity aim to be able to communicate simultaneously to chat, sharing video and image.

\section{2) Chat, Sending Images and files}

Chat, sending images and files are features that are used in personal chat, in this case between two or more personals can communicate and chat to discuss the topic.

\section{3) Recent Updates}

Recent Updates is facility that is most often used, in which the member who is in a particular BBM will be seen doing activity of making Personal Message Display Picture or change will be seen in the recent updates

\section{4) Academic Achievement}

The student academic activity using communication technology is one of the key to improve academic achievement, such as in increasing the learning liveliness value.

\section{E. Hypothesis Research}

Based on the hypothesis, the variables will be demonstrated in this study are as follows:

H0:The use of BBM (Black Berry Messenger) and significant positive effect on students Academic Achievement in SMK Health PGRI Denpasar

H1: The use of BBM (Black Berry Messenger) had no effect on students academic achievement in SMK Health PGRI Denpasar

\section{F. Analysis Technic and Hypothesis Test}

The analysis technique used is the technique of Kendall's Tau correlation analysis. Kendal Tau correlation is used to locate and test the hypothesis relationship between two or more variables if the data in the form ordinal or ranking. In this study, the data form is in scale used is Likert ordinal measurement. Tools used to calculate the correlation coefficient Kendal Tau is SPSS 20.

Reliability test data used[11] by Cronbach Alpha. Cronbach's alpha was developed by Lee in 1951 to provide a measure of internal consistency test or scale. The value of Cronbach Aplha expresses as a number between 0 and 1 . 
According to [4] the value of alpha can be interpreted as follows. Table I shows this.

\section{TABLE I. ALPHA VALUES AND INTERNAL CONSISTENCY}

\begin{tabular}{|c|c|}
\hline Cronbach's alpha & Internal consistency \\
\hline \hline$\alpha \geq 0.9$ & Excellent (High-Stakes testing) \\
\hline \hline $0.7 \leq \alpha<0.9$ & Good (Low-Stakes testing) \\
\hline \hline $0.6 \leq \alpha<0.7$ & Acceptable \\
\hline \hline $0.5 \leq \alpha<0.6$ & Poor \\
\hline \hline$\alpha<0.5$ & Unacceptable \\
\hline
\end{tabular}

IV. RESULT

Data collection is done in SMK PGRI Denpasar Health during dated April 5 to 30 2015.From 100 questionnaires were distributed, only 61 questionnaires were returned and all questions were answered. Based on these data 61 then, data analysis can be done as follows:

\section{A. Profil Respondents Research}

Discussion identity of respondents is based on by gender and by grade

\section{1) Respondents by gender}

Based on the data collected, the number of respondents by gender is shown in Table II below.

TABLE II. RESPONDENT BY GENDER

\begin{tabular}{|l|r|}
\hline \multicolumn{2}{|c|}{ Respondents by gender } \\
\hline Men & $8 \%$ \\
\hline Women & $92 \%$ \\
\hline
\end{tabular}

To make it easier to observe the number, then the data is visualized in the form of pie charts, as shown in Figure 2.Based on these data, it is known that the data analyzed in this study largely derived from female respondents. Not yet known about the effect of gender imbalance respondents to the results of the analysis. In the next study to do research on the influence of gender on using BBM.

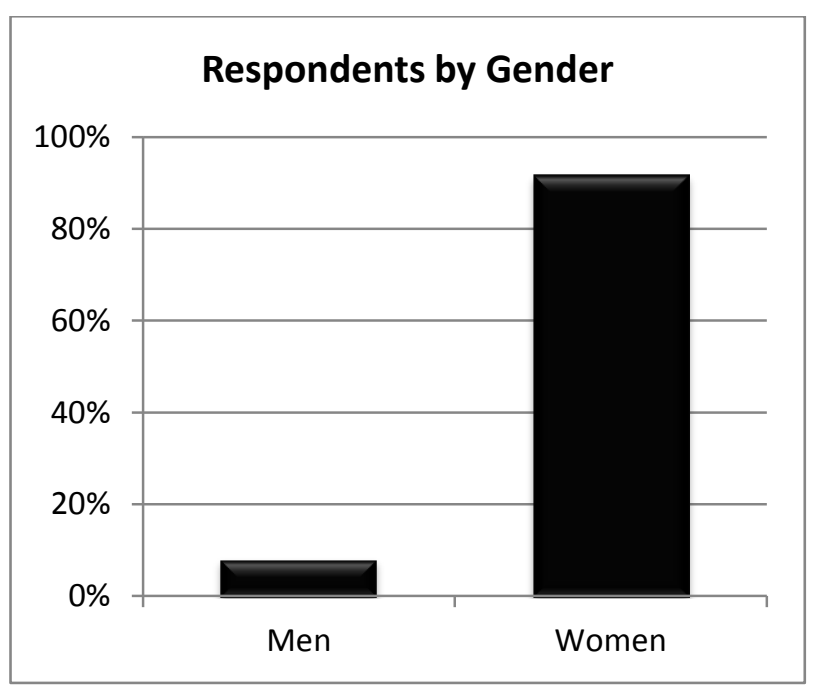

Fig. 3. Visulation Respondens by Gender
2) Respondents by grade

There are 3 grade, but currently only taken two grades of classes XI and XII in SMK Health PGRI Denpasar. Recapitulation of respondents by grade is shown in Table III below.

TABLE III. RESPONDENT BY GRADE

\begin{tabular}{|l|r|}
\hline \multicolumn{2}{|c|}{ Respondents by grade } \\
\hline Grade XI & $33 \%$ \\
\hline Grade XII & $67 \%$ \\
\hline
\end{tabular}

Based on data from Table III, it is known that the majority of respondents were from Grade XII as much as $67 \%$ and as much as $33 \%$ Grade XI. If the data is visualized in a bar chart, the obtained Figure 4 below.

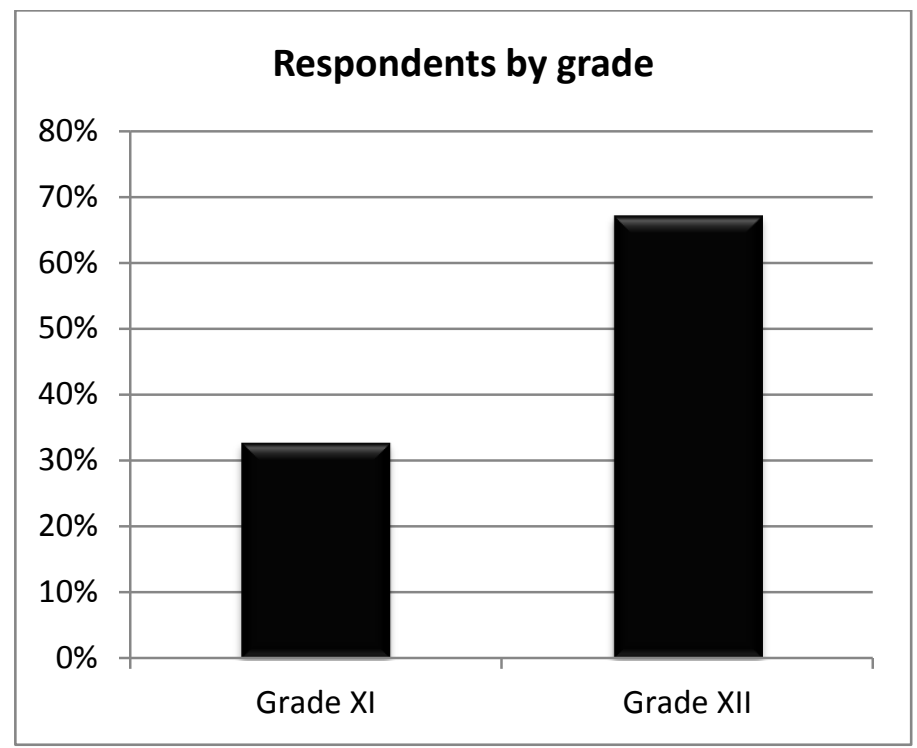

Fig. 4. Visualization Respondents by Grade

\section{B. Result of Realibility test and Validity Data}

\section{1) Realibility Statistics}

Based on the results of reliability test, the obtained results that the Cronbach's Alpha value of the data is equal 0.838. Number can be interpreted that the data obtained are good and can be used. the obtained Figure 5 below.

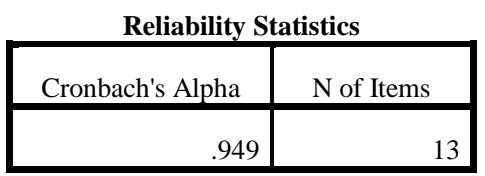

Fig. 5. Result of Reliability Test using SPSS 20

The interpretation of the results is referring to the standard interpretation of internal consistency [4].

\section{2) Result Correlations Test}

Testing Results correlation using techniques Kendal Tau with SPSS 20, obtained the results as figure 6. 


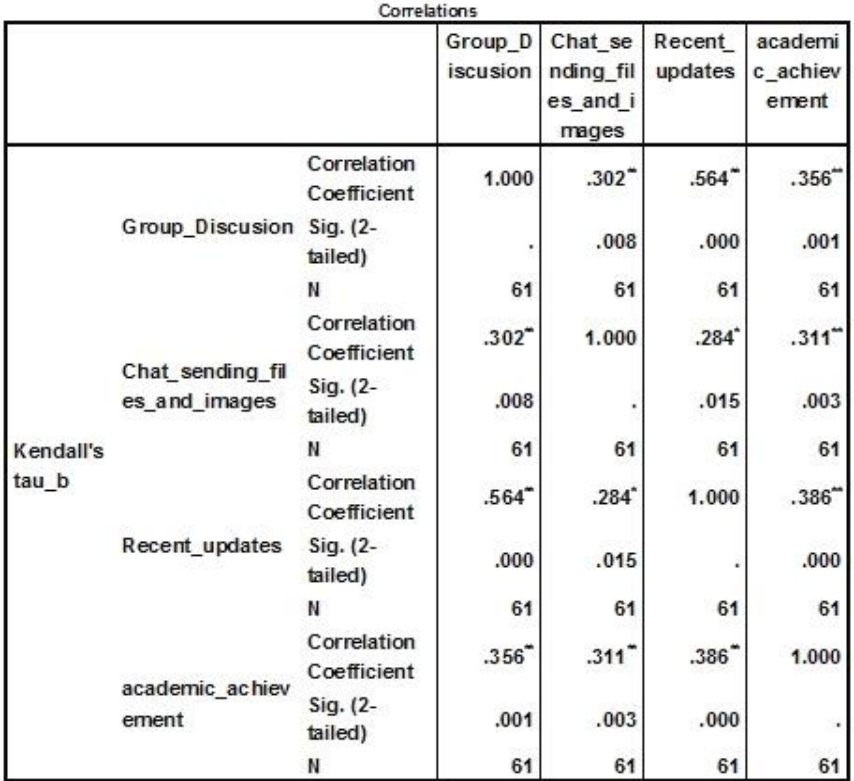

*. Correlation is significant at the 0.01 level (2-tailed).

*. Correlation is signific ant at the 0.05 level ( 2 -tailed).

Fig. 6. Result of Correlation Test
TABLE IV. RESULT OF CORRELATION TEST

\begin{tabular}{|c|c|c|c|}
\hline No & Relations Variable & $\begin{array}{c}\text { Coefficeint } \\
\text { Relation }\end{array}$ & Conclusion \\
\hline 1 & $\begin{array}{c}\text { Group_discusion with } \\
\text { academic_achievement }\end{array}$ & 0.356 & Positive \\
\hline 2 & $\begin{array}{c}\text { Chat_sending_files_and_imag } \\
\text { es with }\end{array}$ & 0.311 & Positive \\
\hline 3 & $\begin{array}{c}\text { Recent_updates with } \\
\text { academic_achievement }\end{array}$ & 0.386 & Positive \\
\hline
\end{tabular}

Based on the above results, it can be interpreted that there is a positive relationship between the variables group_discusion with academic_achievement with large coefficient is equal to 0.356 . Chat_sending_files_and_images variables also have a positive relationship with academic_achievement, with a coefficient of 0.311 and a variable Recent_updates with academic_achievement positive relationship with koefisienn relation of 0386 . $\mathrm{Z}$ value of the third relationship is less than 0.05, suggesting that the relationship between these variables is significant. If the described relationship of these variables on figure 7 : IV:

Based on the above results, it can be interpreteds as table

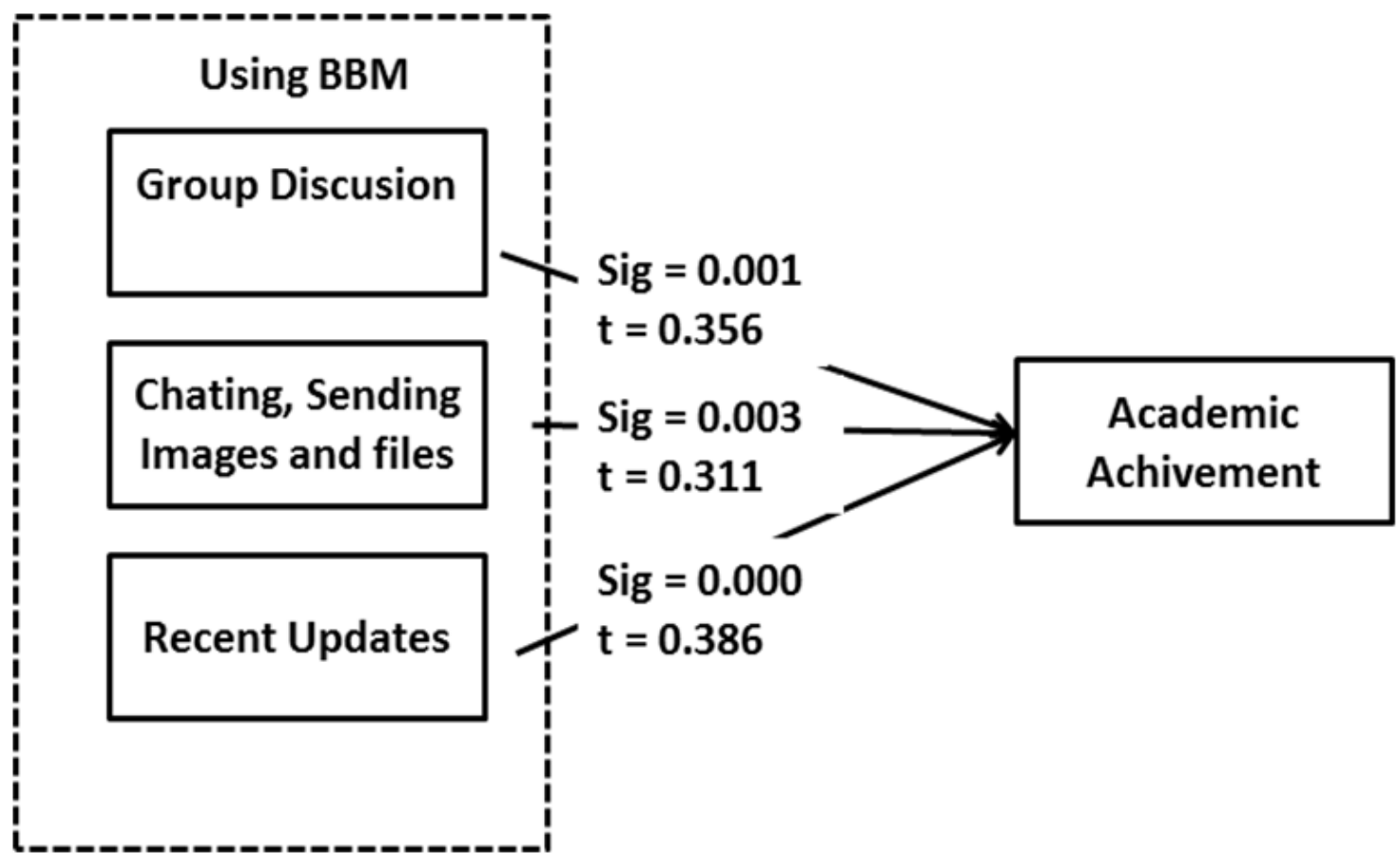

Fig. 7. Relation Result of Effect BBM to Academic Achievement

With the above test results, it can be concluded that the $\mathrm{H} 0$ is rejected and $\mathrm{H} 1$ accepted, namely the use of BlackBerry Messenger in a positive and significant effect on achievement This shows that the learning media BBM (Black Berry Messenger) is best used to increase academic achievement.

\section{CONCLUSION AND RECOMENDATION}

\section{A. Conclusion}

Conclusion of the implementation of the study and research "Effect of BBM (Black Berry Messenger for Improving Academic Achievement in Health SMK PGRI Denpasar" as follows: 
1) From the observations, it showed that BBM technology when using Group Discussion to increase academic achievement is very influential, result is the error rate of 0.001 , below 0.005

2) From the observations, it showed that BBM technology when used in chatting, sending images and files increase the academic achievement of the results, it is very influential and is valued below the error rate is 0.003 , below 0.005

3) From the observations, it indicates that the current BBM technologies of recent updates to increase the academic achievement of the results is very influential it is valued below the error rate is 0.000 , below 0.005

\section{B. Recommendation}

The advice can be given with respect to future research are as follows:

1) On further research would be better if you use more variable as a moderator variable, intervening variable and control variable as a guide as a tool of analysis used together to analyze the data to obtain an appropriate decision.

2) On Further research may also use techniques other than Kendall Tau correlation analysis such as ratio, Spearman Rank, Biseral, Point biserial, Phi and Partial correlation as a guide and measuring devices that can be used to perform the analysis so that the results of such research to be better again.

\section{REFERENCES}

[1] Abreu, F. B. e., "Quantitative Approaches In Object-Oriented Software Engineering” London: Sterling, VA, Kogan Page Science, 2003.

[2] Asio, V. "Research Productivity In Soil Science In The Philippines." Scientometrics 100(1): 261-272, 2014

[3] Bernard, H. R, "Research Methods In Anthropology : Qualitative And Quantitative Approaches”, Lanham, Md., AltaMira Press, 2011

[4] Cortina, J.M. ,"What Is Coefficient Alpha? An Examination Of Theory And Applications" Journal of Applied Psychology 78, 98-104,1993

[5] Godinjak, A., et al., "Insulin Resistance And Lipid Accumulation Product In Corelation To Body Mass Index In Women With Polycystic Ovary Syndrome." Med Arch 66(6): 409-411, 2012

[6] Hoyle, R. H, "Handbook Of Personality And Self-Regulation", Chichester, U.K. : Malden, MA, Wiley-Blackwell, 2010

[7] Ifenyi-obi C.C, Olatunji S.O and Enyindah, F.,'Effect Of Blackberry Messenger Usage On The Academic Activities Of Agriculture Students In University Of Portharcourt", USA, PP 07-11, 2014

[8] Onyeka,A.C., Nlebedim, V.U. \& Izunobi,C.H., "Estimation Of Population Ratio In Simple Random Sampling Using Variable Transformation", USA, 2013

[9] Orelus, P. W, "Academic Achievers : Whose Definition? : An Ethnographic Study Examining The Literacy (Under) Development Of English Language Learners In The Era Of High-Stakes Tests. Rotterdam": Boston, Sense, 2010

[10] Smith, G. A. And D. Sobel, "Place- And Community-Based Education In Schools" New York, NY, Routledge, 2010

[11] Tavakol, M., Dennick, R. (2011), "Making Sense of Cronbach's alpha", International Journal of Medical Education. Pp. 53-55, 2011

[12] Tohwidi, Afsaneh, "Distance Education Technologies And Media Utiliation In Higher Education”, Iran, 2010 